\title{
Some Results of Univalent and Starlike Integral Operator
}

\author{
E. A. Eljamal, ${ }^{1}$ M. Darus, ${ }^{1}$ and D. Breaz ${ }^{2}$ \\ ${ }^{1}$ School of Mathematical Sciences, Faculty of Science and Technology, The National University of Malaysia, \\ Selangor "D. Ehsan," 43600 Bangi, Malaysia \\ ${ }^{2}$ Department of Mathematics-Informatics, Faculty of Science, 1 Decembrie 1918 University of Alba Iulia, 510009 Alba Iulia, Romania
}

Correspondence should be addressed to D. Breaz; breazdaniel@yahoo.com

Received 14 October 2012; Accepted 24 October 2012

Academic Editor: Nikolai Tarkhanov

Copyright (C) 2013 E. A. Eljamal et al. This is an open access article distributed under the Creative Commons Attribution License, which permits unrestricted use, distribution, and reproduction in any medium, provided the original work is properly cited.

The main objective of the present paper is to study the mapping properties of functions belonging to certain classes under a family of univalent and starlike integral operator. Relationships of these classes are also pointed out.

\section{Introduction and Definitions}

Let $A$ denotes the class of functions $f$ normalized by

$$
f(z)=z+\sum_{n=2}^{\infty} a_{n} z^{n}
$$

which are analytic in the open unit disk

$$
U=\{z:|z|<1\} \text {. }
$$

Also let $S$ denotes the class of all functions in $A$ which are univalent in $U$. Then a function $f \in S$ is said to be starlike in $U$ if and only if

$$
\operatorname{Re}\left\{\frac{z f^{\prime}(z)}{f(z)}\right\}>0 \quad(z \in U)
$$

We denote by $S^{*}$ the class of all functions in $S$ which are starlike in $U$. A function $f \in S$ is said to be starlike of order $\alpha$ in $U$ if and only if

$$
\operatorname{Re}\left\{\frac{z f^{\prime}(z)}{f(z)}\right\}>\alpha \quad(z \in U),
$$

for some $\alpha(0 \leq \alpha<1)$. We denote by $S^{*}(\alpha)$ the class of all functions in $S$ which are starlike of order $\alpha$ in $U$. Clearly, we have $S^{*}(\alpha) \subseteq S^{*}(0)=S^{*}(0 \leq \alpha<1)$.
With a view to introducing an interesting family of analytic functions, we should recall the concept of subordination between analytic functions. Given two functions $f$ and $g$, which are analytic in $U$, the function $f$ is said to be subordinate to $g$ if there exists a function $w$, analytic in $U$ with $w(0)=0$ and $|w(z)|<1(z \in U)$ such that $f(z)=g(w(z))$, $(z \in U)$, and symbolically written as the following:

$$
f \prec g \quad(z \in U) \quad \text { or } \quad f(z) \prec g(z) \quad(z \in U) .
$$

It is known that $f(z) \prec g(z)(z \in U) \Rightarrow f(0)=g(0)$ and $f(U) \subset g(U)$.

Definition 1 (see [1]). For $-1 \leq B<A \leq 1$, a function $p(z)$, analytic in $U$ with $p(0)=1$, is said to belong to the class $\beta(A, B)$ if

$$
p(z) \prec \frac{1+A z}{1+B z} \quad(-1 \leq B<A \leq 1) .
$$

To prove our main result, we need the following.

Lemma 2 (see [2]). Let the functions $N$ and $D$ be analytic in $U$, and let $D$ map $U$ onto a starlike region. Suppose also that

$$
\begin{aligned}
N(0) & =D(0)=0, \quad \frac{N^{\prime}(z)}{D^{\prime}(z)}=k, \\
\frac{N^{\prime}(z)}{k D^{\prime}(z)} & \in \beta(A, B) \quad(k \geq 1) .
\end{aligned}
$$


Then,

$$
\frac{N(z)}{k D(z)} \in \beta(A, B)
$$

for all $z \in U$.

Lemma 3 (see [3]). Let

$$
p_{j}(z) \in \beta(A, B) \quad(j=1,2) .
$$

Then, for $\alpha>0$ and $\beta>0$,

$$
\frac{\alpha p_{1}(z)+\beta p_{2}(z)}{\alpha+\beta} \in \beta(A, B),
$$

for all $z \in U$.

Lemma 4 (see [4]). Let the functions $M$ and $N$ be analytic in U with

$$
M(0)=N(0)=0,
$$

and let $\gamma$ be a real number. Suppose also that $N$ maps $U$ onto a region which is starlike with respect to the origin. Then,

$$
\begin{aligned}
& \operatorname{Re}\left\{\frac{M^{\prime}(z)}{N^{\prime}(z)}\right\}>\gamma \quad(z \in U) \\
& \Longrightarrow \operatorname{Re}\left\{\frac{M(z)}{N(z)}\right\}>\gamma \quad(z \in U)
\end{aligned}
$$

\section{Main Result}

We begin by introducing a new integral operator

$$
I(f, g)(z)=\frac{\alpha+1}{z^{\alpha}} \int_{0}^{z}\left(f(t) e^{g(t)}\right)^{\alpha} d t=z+\sum_{n=2}^{\infty} c_{n} z^{n}
$$

where $f$ and $g \in A$.

Bear in mind, there are various types of integral operators studied by many different authors such as [5-9], few to mention, that motivate us to come out with the abovementioned integral operators.

Now let us begin with our first result relating to the integral operator of (13).

Theorem 5. Let the functions $f$ and $h$ be in the class $S^{*}$. Then, the function $I(f, g)$ defined by (13) is also in the class $S^{*}$.

Proof. By logarithmic differentiation, we find from (13) that

$$
\frac{z I^{\prime}(f, g)(z)}{I(f, g)(z)}=\frac{N(z)}{D(z)}
$$

where

$$
\begin{gathered}
N(z)=z\left(f(z) e^{g(z)}\right)^{\alpha}-\alpha \int_{0}^{z}\left(f(t) e^{g(t)}\right)^{\alpha} d t \\
D(z)=\int_{0}^{z}\left(f(t) e^{g(t)}\right)^{\alpha} d t .
\end{gathered}
$$

Clearly, we have $N(0)=D(0)=0$, and $D$ satisfies the starlikeness condition of Lemma 4.

Next, let $z h(z)=e^{g(z)}$, where $h(z)$ is analytic function in $D=\{z: 0<|z|<1\}$, and $h(z) \neq 0, h(0)=1$. From (15), it is easily seen that

$$
\begin{aligned}
\operatorname{Re}\left\{\frac{N^{\prime}(z)}{D^{\prime}(z)}\right\} & =\alpha \operatorname{Re}\left\{\frac{z f^{\prime}(z)}{f(z)}\right\}+\alpha \operatorname{Re}\left\{\frac{z h^{\prime}(z)}{h(z)}\right\}+1 \\
& =\gamma>0 \quad(z \in U),
\end{aligned}
$$

hence by Lemma 4, we obtain

$$
\operatorname{Re}\left\{\frac{N(z)}{D(z)}\right\}=\operatorname{Re}\left\{\frac{z I^{\prime}(f, g)(z)}{I(f, g)(z)}\right\}>0 \quad(z \in U)
$$

that is

$$
\operatorname{Re}\left\{\frac{z I^{\prime}(f, g)(z)}{I(f, g)(z)}\right\}>0 \quad(z \in U)
$$

which evidently proves Theorem 5 .

Theorem 6. Let the functions $f$ and $g$ be in the class $S^{*}(A, B)$. Then, $(1 / 2 \alpha)\left\{z I^{\prime}(f, g)(z) / I(f, g)(z)-1\right\}$ is in the class $\beta(A, B)$.

Proof. Since

$$
f(z) \in S^{*}(A, B), \quad g(z) \in S^{*}(A, B),
$$

we find from Definition 1 that

$$
\frac{z f^{\prime}(z)}{f(z)} \in \beta(A, B), \quad \frac{z g^{\prime}(z)}{g(z)} \in \beta(A, B) .
$$

By logarithmic differentiation, we find from (13) that

$$
\frac{z I^{\prime}(f, g)(z)}{I(f, g)(z)}-1=\frac{N(z)}{D(z)}
$$

where

$$
\begin{gathered}
N(z)=z\left(f(z) e^{g(z)}\right)^{\alpha}-(\alpha+1) \int_{0}^{z}\left(f(t) e^{g(t)}\right)^{\alpha} d t \\
D(z)=\int_{0}^{z}\left(f(t) e^{g(t)}\right)^{\alpha} d t .
\end{gathered}
$$

Next, let $h(z)=e^{g(z)}$, and from (15), it is easily seen that

$$
\operatorname{Re}\left\{\frac{N^{\prime}(z)}{D^{\prime}(z)}\right\}=\alpha \operatorname{Re}\left\{\frac{z f^{\prime}(z)}{f(z)}\right\}+\alpha \operatorname{Re}\left\{\frac{z h^{\prime}(z)}{h(z)}\right\} .
$$

Now rewrite the equality in (23) in the form

$$
\frac{1}{2 \alpha} \frac{N^{\prime}(z)}{D^{\prime}(z)}=\frac{1}{2 \alpha}\left\{\alpha \frac{z f^{\prime}(z)}{f(z)}+\alpha \frac{z h^{\prime}(z)}{h(z)}\right\},
$$


so that by (20) and Lemma 3, we have

$$
\frac{1}{2 \alpha} \frac{N^{\prime}(z)}{D^{\prime}(z)} \in \beta(A, B) \quad(\alpha>0) .
$$

It is easily seen that $D$ and $N$ satisfy conditions of Lemma 2. It follows from (21), (25), and Lemma 2 that

$$
\frac{1}{2 \alpha} \frac{N(z)}{D(z)} \in \beta(A, B)
$$

which evidently proves Theorem 6 .

\section{Acknowledgment}

The work presented here was supported by LRGS/TD/2011/ UKM/ICT/03/02.

\section{References}

[1] W. Janowski, "Some extremal problems for certain families of analytic function. I," Annales Polonici Mathematici, vol. 28, pp. 297-326, 1973

[2] S. S. Miller and P. T. Mocanu, "Second order differential inequalities in the complex plane," Journal of Mathematical Analysis and Applications, vol. 65, no. 2, pp. 289-305, 1978.

[3] K. I. Noor, "On some univalent integral operators," Journal of Mathematical Analysis and Applications, vol. 128, no. 2, pp. 586-592, 1987.

[4] G. L. Reddy and K. S. Padmanabhan, "On analytic functions with reference to the Bernardi integral operator," Bulletin of the Australian Mathematical Society, vol. 25, pp. 387-396, 1982.

[5] D. Breaz, S. Owa, and N. Breaz, "A new integral univalent operator," Acta Universitatis Apulensis. Mathematics. Informatics, vol. 16, pp. 11-16, 2008.

[6] A. Mohammed and M. Darus, "Some properties of certain integral operators on new subclasses of analytic functions with complex order," Journal of Applied Mathematics, vol. 2012, Article ID 161436, 9 pages, 2012.

[7] A. Mohammed and M. Darus, "New properties for certain integral operators," International Journal of Mathematical Analysis, vol. 4, no. 41-44, pp. 2101-2109, 2010.

[8] A. Mohammed and M. Darus, "A new integral operator for meromorphic functions," Acta Universitatis Apulensis, no. 24, pp. 231-238, 2010.

[9] N. Breaz, D. Breaz, and M. Darus, "Convexity properties for some general integral operators on uniformly analytic functions classes," Computers and Mathematics with Applications, vol. 60, no. 12, pp. 3105-3107, 2010. 


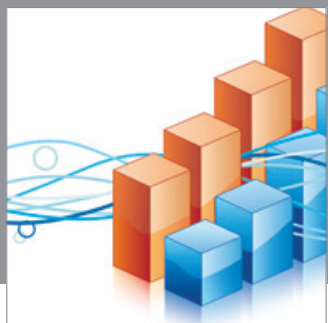

Advances in

Operations Research

mansans

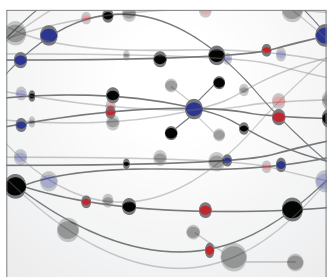

The Scientific World Journal
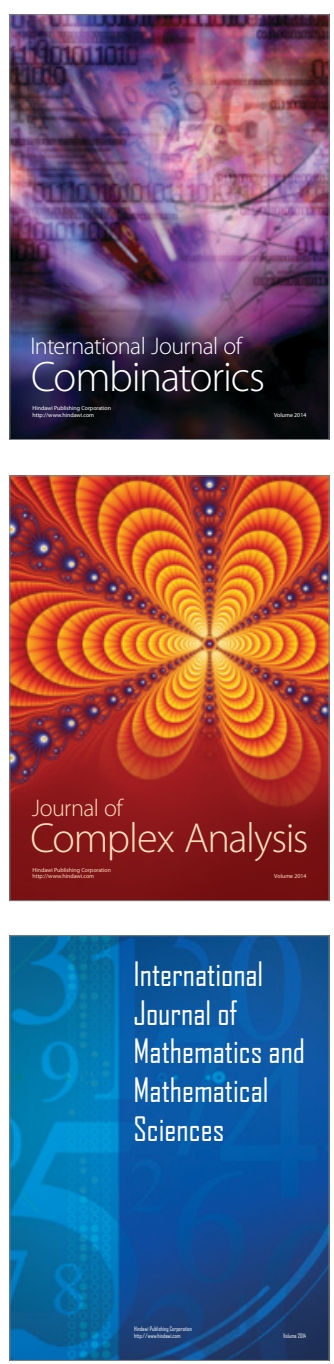
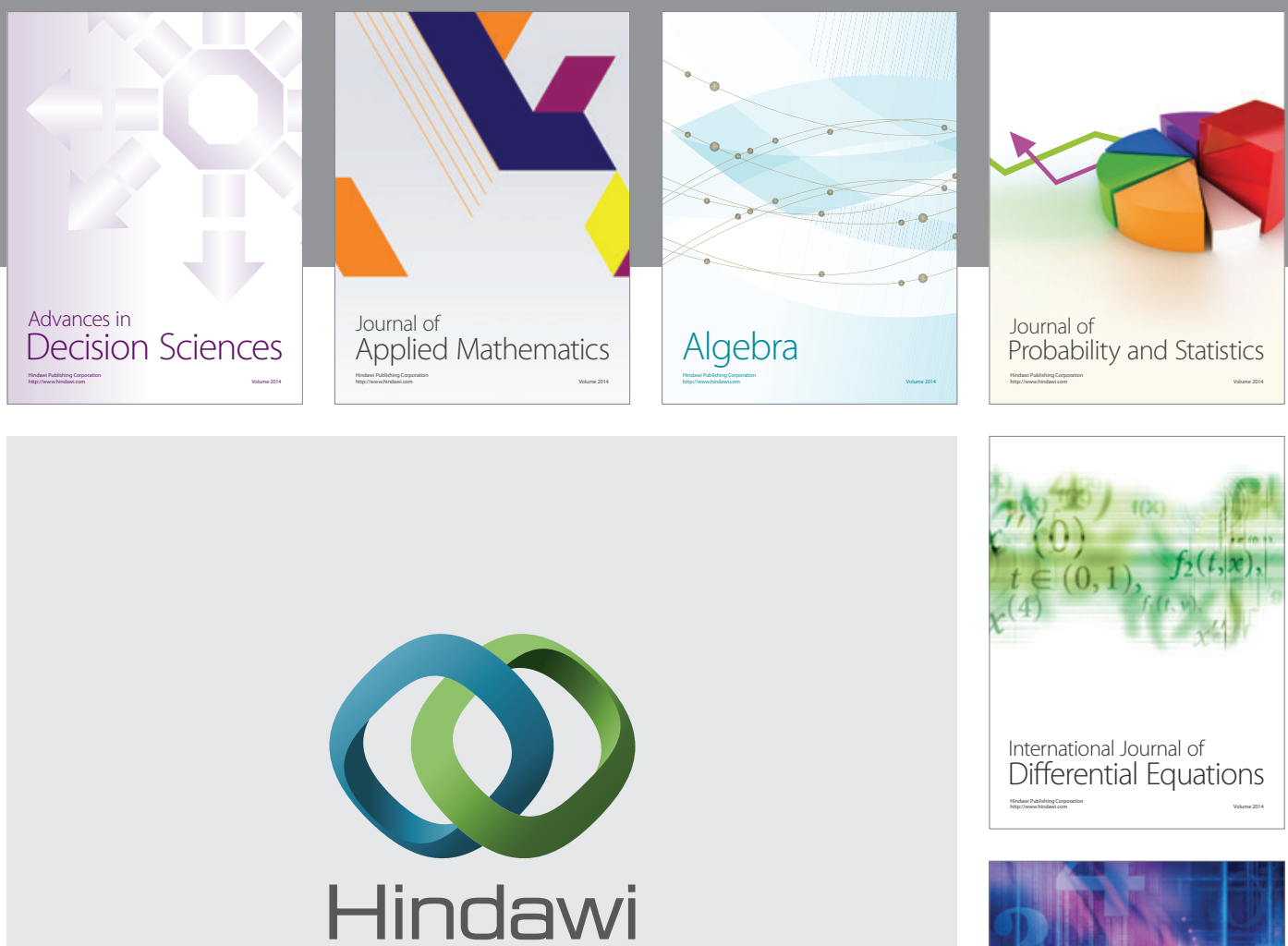

Submit your manuscripts at http://www.hindawi.com
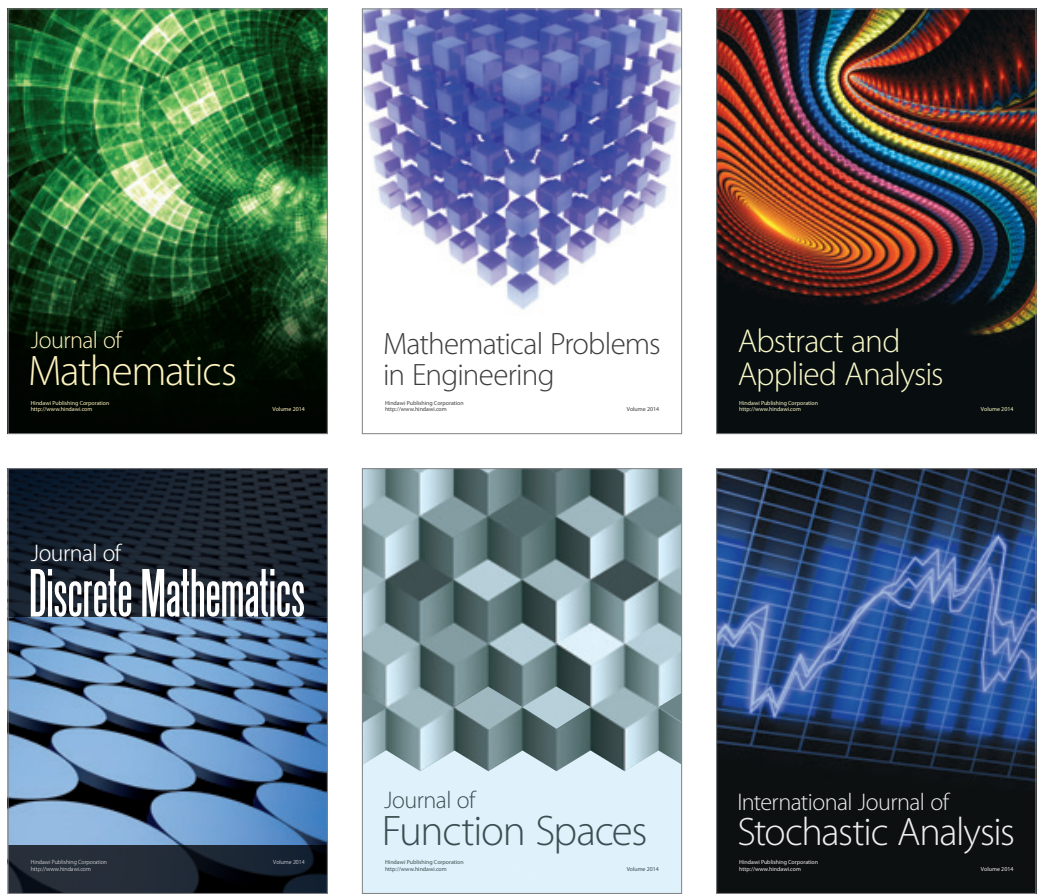

Journal of

Function Spaces

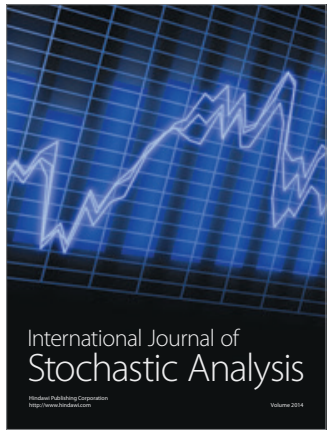

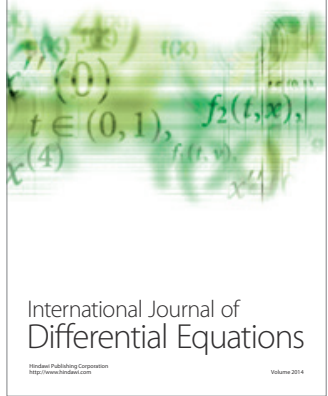
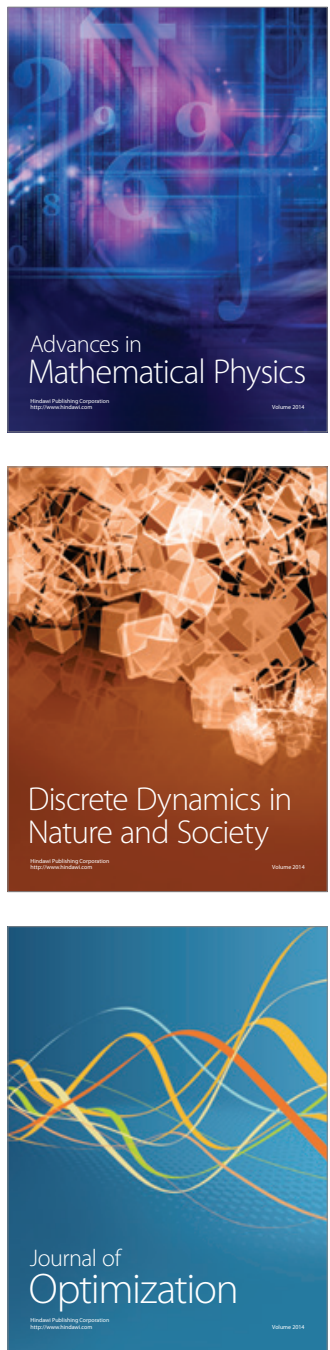